\title{
Goldenhar syndrome in a Nigerian child: a case report
}

\begin{abstract}
A three year old Nigerian girl presented with features suggestive of Goldenhar syndrome. The patient presented with lacrimation in the left eye and this prompted the maternal grandmother to bring the child to the hospital. No similar occurrence in the family of the patient. Multidisciplinary approach was adopted in the care of the patient. However no significant systemic abnormality was discovered. The need to create awareness about this rare disease cannot be overemphasized.
\end{abstract}

Keywords: lid defect, preauricular tags, unilateral, Nigerian, child
Volume 7 Issue 2 - 2017

\author{
Charles Oluwole Omolase,' Sotiloye OA,' \\ Omolase BO, ${ }^{2}$ Bassey UF,' Ojo AD' \\ 'Department of Ophthalmology, Federal Medical Centre, \\ Nigeria \\ ${ }^{2}$ Department of Radiology, Federal Medical Centre, Nigeria
}

Correspondence: Charles Oluwole Omolase, Department of Ophthalmology, Federal Medical Centre, Michael Adekunle Ajasin way, Owo, Ondo State, Nigeria, Tel 08033788860 , Email omolash2000@yahoo.com

Received: June 23, 2017 | Published: July 03, 2017

\section{Introduction}

Goldenhar syndrome is a rare developmental disorder. The disorder manifests with malformation of the face due to abnormal development of the first and second branchial arches. The disorder is relatively uncommon and the incidence is 1 in 5,600. ${ }^{1}$ Higher incidence of Goldenhar syndrome $(14.7 / 100,00)$ was reported in children of war veterans deployed to Persian gulf as opposed to those not deployed: $4.8 / 100,000 .^{2}$ The disorder is mostly sporadic with some familial occurrence. $^{3}$ Authors have reported autosomal recessive or dominant inheritance. ${ }^{4}$ The aetiology of the disorder is not clearly spelt out, however early developmental arrest in the $4^{\text {th }}$ week of gestation and diseases like diabetes mellitus in the $8^{\text {th }}$ to $12^{\text {th }}$ week affecting $1^{\text {st }}$ and $2^{\text {nd }}$ branchial arches as well as non-dysfunction of chromosome may play significant role in the underlying mechanism of the disease. ${ }^{3}$ Goldenhar syndrome was first defined precisely by Maurice Goldenhar in $1952 .{ }^{5}$ It is characterised by multiple affectation of the eyes, ear, heart as well as skeletal and nervous systems. ${ }^{5}$ The vertebral anomalies associated with the syndrome were highlighted in 1963 by Gorlin and Pinberg and thus it was named oculoauriculovertebral syndrome. ${ }^{6}$ There is a male preponderance of $3: 2.5$ The genetic linkage is not established in the aetiology. However the multifactoral aetiology which involves nutritional and environmental factors that adversely affects blastogenesis. ${ }^{7,8}$

\section{Case history}

Three (3) year old Nigerian girl was brought to the Eye Clinic of Federal Medical Centre, Owo by the maternal grandmother on account of lacrimation in the left eye in March, 2017. The lacrimation was noticed shortly after the birth of the child and she had been on topical eye medication since then. The patient is the first child of the mother in a polygamous setting. The father had four other children from the first wife. The father is a driver while the mother is a petty trader. The period of pregnancy was said to be uneventful. The child was delivered through caesarean section. She attained developmental milestones as at when due. The child had been performing well since her enrolment in school. The hearing and mental state were considered normal by the parents.

No known family history of similar occurrence. Examination of the child revealed a young active girl with defect in the lower lid (LE) as shown in Figure 1. There were two pre auricular tags on the left side as shown in Figure 2. There was mild discharge in the left eye. The other parts of both eyes were normal. The visual acuity assessed with kay pictures was $6 / 9$ in both eyes. Further physical examination did not reveal any associated systemic anomaly. The patient was reviewed by the Paediatrician, ENT Surgeon and Dental surgeon. No significant findings were reported except by the Dental surgeon who reported diastema. The patient was placed on Chloramphenicol eye drop to be applied four times daily for 2 weeks in view of the discharge from the left eye. The child was advised to come for periodic reviews.

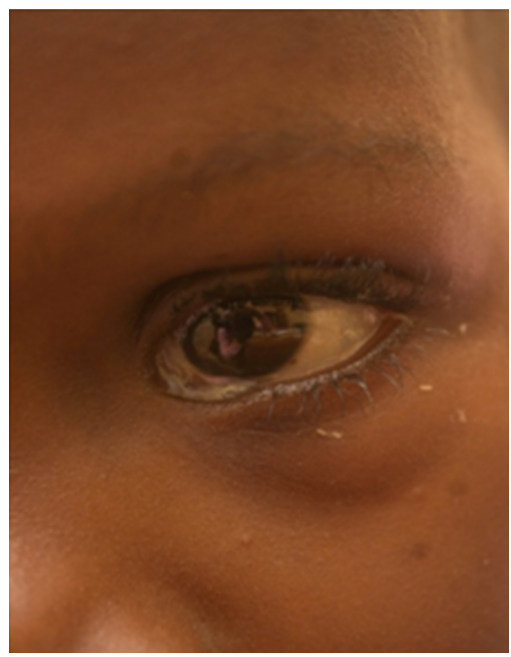

Figure I Examination of the child revealed a young active girl with defect in the lower lid (LE). 


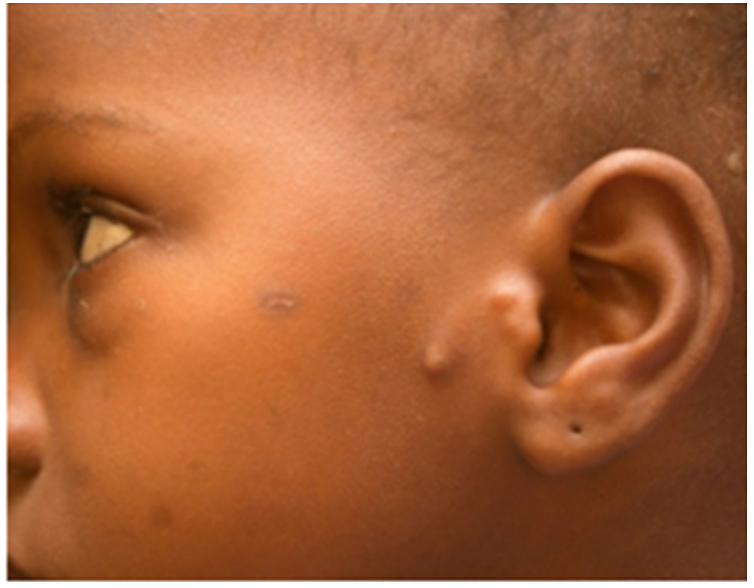

Figure $\mathbf{2}$ There were two pre auricular tags on the left side.

\section{Discussion}

The disorder manifests with incomplete development of the ear, nose, soft palate, lip and mandible. The disorder classically presents with hemi facial microsoma, epibulbar dermoid as well as ear deformities like preauricular appendages.${ }^{6,7}$ Ocular manifestation includes epibulbar dermoid, coloboma, microphthalmus, cataract, iris anomalies, enophthalmus, optic nerve hypoplasia and strabismus. ${ }^{6}$ In about $24 \%$ of cases, there is affectation of the ribs and vertebrae. ${ }^{1}$ Teratogenic agents like primidone, retinoic acid and thalidomide have been implicated in the aetiology of this disorder. ${ }^{9}$ The malformations of the disorder typically affects both sides of the body in $10-33 \%$ of cases and usually asymmetrical. ${ }^{10}$ The right side had been reported to be more affected that the left side. ${ }^{11}$ In this case the notable findings in the eye and ear were limited to the left side while the right side appeared normal.

Rare delayed development of tooth had been reported in some cases. ${ }^{12}$ However our patient did not present with any significant dental findings except for diastema. The disorder tend to occur sporadically but may be inherited occasionally. ${ }^{13}$ The case reported appeared to be an index case in her family as there was no similar occurrence prior to this.

The prevalence ranges from 5,600 to 45,000 live births with male preponderance $(3: 2) .{ }^{14}$ There had been previous reports of this rare condition in Nigeria by Ibrahim et al. ${ }^{13}$ Adeoye ${ }^{15}$ and Bekibele et al. ${ }^{16}$ Adeoye reported the case in a 3 month old baby and traditional medication in the first trimester of pregnancy was implicated in the aetiology. The case reported in Ibadan by Bekibele et al. was a woman who presented late at 24 years of age. Different types of treatment are adopted based on the stage of development. ${ }^{17}$ There is need for constant follow up of the patients. ${ }^{18}$ Prognosis of this disorder is good, if it is not associated with systemic anomalies. ${ }^{19}$ In view of the fact that the patient presented with mild signs and no systemic anomaly the prognosis is thus good. However, since the disorder affects different body systems, multidisciplinary approach in the Management cannot be overemphasized. ${ }^{20}$ This explains why the lead author referred the patient to specialists in other fields. The early presentation of the child is quite commendable and this may be related to lacrimation she experienced and discovered by an observant grandmother.

\section{Conclusion}

We conclude that prompt presentation and treatment of patients with Goldenhar syndrome is desirable. There is need to create more awareness about the condition among health care providers and the populace in view of its rarity. Multidisciplinary approach should be adopted in the management of affected patients most especially those with associated systemic anomalies.

\section{Acknowledgments}

None.

\section{Conflicts of interest}

The authors declare no conflicts of interest.

\section{References}

1. Atherton DJ, Moss C. Waevoid and other developmental defects. In: Burns T, et al. editors. Blackwell Science, Oxford, USA, 2004;1-5.

2. Araneta MR, Moore CA, Olney RS, et al. Goldenhar syndrome among infants born in military hospitals of gulf war veterans. Teratology. 1977;56(4):244-251.

3. Muhammad AM, Ghufransaed, Shahid JA, et al. Goldenhar syndrome: case reports with review of literature. Journal of Parkistan Association of Dermatologists. 2008;18:53-55.

4. Bayralctar S, Bayralctar St, Ataoglu E, et al. Goldenhar syndrome associated with multiple congenital abnormalities. J Trop Pediatr. 2005;51(6):377-379.

5. Lakshimi R, Prabha Subhash, Anupana D, et al. Goldenhar Syndrome: A case report. Int J Anal Res. 2016;4(1):2076-2079.

6. Tsai FJ, Tsai CH. Autosomal dominant inherited Oculo-auriculo-vertebral spectrum report of one family. Zhonghua Min Guo Xiao Er Ke Yi Xue Hui Za Zhi. 1993;34(1):27-31.

7. Jaison SG, Batra N. Goldenhan syndrome with multiple additional anomalies. Indian J Ophthalmol. 1996;44(1):42-44.

8. Rollnick BR, Kaye CI, Nagatoshi K, et al. Oculoariculovertebral dysplasia and phenotopic characteristic in 294 patients. Am J med Genet. 1987;26(2):361-175.

9. Kapur R, Kapur R, Sheikh S, et al. Hemifacial microsomia: A case report. J Indian Soc Pedod Prevent Dent. 2008;26(Suppl 1):34-40.

10. Dali M, Chackov, Rao A. Goldenhar syndrome; A report of a rare case. Journal Nepal Dental Association. 2009;10(2):128-130.

11. Rao VA, Rao S, Lamba PA. Goldenhar's syndrome. Indian J of Ophthlmol. 1982;30:147-149.

12. Alkumru H, Colok G. Hemifacial Microsoma and hydontia: a case report. J Oral Rehabil. 1992;19(6):671-675.

13. Ibrahim A, Asami MO (2014) Goldenhar Syndrome in a 2 years old Nigerian girl. Saudi J Health Sci 3(1): 50-52.

14. Gorlin RJ, Cohen MM, Levin LS. Syndromes of the Head and Neck. Oxford University Press, New York, USA. 1990.

15. Adeoye AO. Goldenhar's syndrome: Case report. East Afr Med J. 2002;79:502-504

16. Bekibele CO, Adewola SA, Amanor Boadu SD, et al. Goldenhar Syndrome: A case report and Literature review. West Afr J Med. 2002;24(1):77-80. 
17. Goldenhar Syndrome. FACES:The National Craniofacial Association February. 2016.

18. Tewfik TL. Manifestation of Craniofacial syndromes. Apr. 20, [last retrieved on 2016 May 05]. 2005.
19. Ansari S, Dhungel K, Ahmed K, et al. Goldenhar Syndrrome presenting as limbal dermoid cyst: A case report with clinical and radiological findings. International Journal of case reports and images. 2013;4(7):384-387.

20. Saxena R, David MP. Goldenhar syndrome- a rare case report. J Genet Syndr Gene Ther. 2012;3:113. 